\title{
LVI. On the penetration of heat across layers of gas
}

\section{G. Johnstone Stoney M.A. F.R.S.}

To cite this article: G. Johnstone Stoney M.A. F.R.S. (1877) LVI. On the penetration of heat across layers of gas, Philosophical Magazine Series 5, 4:27, 424-443, DOI: $10.1080 / 14786447708639365$

To link to this article: http://dx.doi.org/10.1080/14786447708639365

曲 Published online: 13 May 2009.

Submit your article to this journal $\lceil\pi$

Џ Article views: 2

Q View related articles $\square$

Citing articles: 1 View citing articles 5 
of the earth's surface which might be drawn from the great absorptive power of the air for rays of low refrangibility, such as are largely present in the solar rays, and conclude this paper with a short summary of the chief results of my experiments.

The thermal conductivity of hydrogen and of other gases is far too small to admit of its being proved by the method Magnus adopted. The assumption that the conductivity of hydrogen is similar to that of the metals, if by this statement any thing more is meant than that hydrogen, like solid and liquid bodies, is capable of transmitting heat from molecule to molecule, is therefore not justified.

On the other hand, hydrogen possesses a diathermancy closely approaching that of a vacuum.

Dry air absorbs from 50 to 60 per cent. of the rays of heat which it receives from a source beated to the boiling-point of water.

The absorptive power of moist air surpasses that of dry air by a trifling percentage, but by no means to such a degree as hitherto had been assumed by several physicists.

Rock-salt is not absolutely diathermanous for the so-called dark rays of heat; its thermal colour rather resembles that of dry air.

Giessen, March 30, 1876.

LVI. On the Penetration of Heat across Layers of Gas. By G. Johnstone Stoney, M.A., F.R.S., \&c., Secretary Royal Dublin Society*.

\section{Part I. Theory.}

1. UEAT will pass between bodies at different temperaIt tures by direct contact, by radiation and absorption, or by contact with a fluid and convection through it. That heat may be transported in these several ways has long been known; and the laws of the transfer have been made the subject of repeated and careful investigation by experiment and by the deductive method. And last year two papers $\dagger$ were published by the anthor of the present memoir, in which it was shown that heat will also escape, under new conditions, across a Crookes's layer, if the layer be restricted in width. In those papers the mechanical actions that arise, and upon which Mr. Crookes had made many experiments, were made the subject of study; and the present communication aims at

* From the Scientific Transactions of the Royal Dublin Society for 1877. Communicated by the Author.

$\dagger$ See Phil. Mag, for March and April 1876. 
extending the investigation to the second branch of the subject, viz. the transfer of heat which accompanies those mechanical actions.

2. When gas is in contact with a body $A$ at a different temperature from itself, it is a familiar fact that convection currents rapidly set in. The first step of the process is the almost instantaneous formation of that layer which I bave called Crookes's layer-a layer of the gas of varying density and temperature, being on one side at the temperature of the body $A$, and on the other side at the temperature of the surrounding gas. It is because this layer has a different density from the rest of the gas, and because of the attraction of the earth, that those streams set in which are called convection currents; and accordingly, if the experiment could be made at a station where there is no gravity, these convection currents would not arise, although the Crookes's layer would then also be fully developed. It will be convenient to inquire first what will occur under these simplified conditions, and afterwards to take into consideration whether any modification has to be made to allow for the effect of the neighbouring earth. To give to the problem definiteness and the utmost simplicity, I will suppose that a body $\mathrm{A}$ at temperature $\theta_{1}$ presents a large flat surface to an atmosphere of gas which is at a lower temperature $\theta_{2}$, and exposed everywhere to a constant pressure, but which is uninfuenced by gravity. Let us further regard this gas as a perfect non-conductor of heat.

3. If the excess of temperature is supposed to be suddenly imparted to $A$, there will be a brief interval of adjustment within the gas, after which the condition of the gas will settle down into the state in which the Crookes's layer will have been fully formed. The Crookes's lnyer in this case will obviously consist of a flat stratum of the gas in contact with the hot surface of $\mathrm{A}$; and within this stratum the temperature will gradually decrease from within outwards, from $\theta_{1}$, the temperature of $\mathrm{A}$, down to $\theta_{2}$, the temperature of the surrounding gas. This gradual falling-off of the temperature implies a corresponding gradual augmentation of the density, since we have supposed the gas to be everywhere subjected to the same pressure. If the gas could * admit of the formation of a complete Crookes's layer, then we know, from the familiar experiments which show gases to be bad conductors of heat, that after the brief interval of adjustment a permanent state would ensue, in which there would be no further change of density, or motion of heat except by radiation. Accordingly, if an isothermal surface be now drawn within the layer

* See page 427 , the last paragraph of section 4 . 
(which, in the simple case we have supposed, will be a plane parallel to $A$ ), there will fly the same number of molecules per second in both directions, across an element $\delta S$ of this surface, the momentum of the two processions which pass through $\delta \mathrm{S}$ in a second will be the same, and their kinetic energy also will be the same. Their number will be the same; for otherwise the density would be still undergoing change, and we have supposed that the period of adjustment is over. Their momentum will be the same, because the pressure is everywhere constant; and their kinetic energy is the same, because there is no transfer of heat across $\mathrm{S}$.

4. Hence the change of temperature and density in passing along $\delta x$, an element of the normal to $\delta \mathrm{S}$, must be such as to secure these three conditions. In investigating the law of this variation, we have to take into account:-

$P$, the pressure everywhere through the gas;

$\theta$, the temperature (measured from absolute zero) on the isothermal surface $\mathbf{S}$;

$\rho$, the density of the gas on the isothermal surface $S$;

$x$, the distance of $\mathrm{S}$ from $\mathrm{A}$; and

$G$, a quantity which changes from one gas to another, but is almost constant in each gas, within a wide range of temperature and pressure.

When the gas and its tension are given, $G$ and $P$ are constants; and $\rho$ is a known function of $G, P$, and $\theta$. Hence only two of the foregoing quantities are independent-suppose $\theta$ and $x$, instead of which we may use $\frac{d x}{d \theta}$ and $\theta$. It is easy to see, by taking particular instances, that $\frac{d x}{d \theta}$ and $\theta$ will remain independent of one another, if only two of the conditions in $\$ 3$ need to be fulfilled; but if all three have to be fulfilled, we find by experiment that a definite Crookes's layer is formed, and that, therefore, in each gas and at each pressure $\frac{d x}{d \theta}$ is a definite function of $\theta$. In other words,

$$
\frac{d x}{d \theta}=\psi(\theta, \mathrm{G}, \mathrm{P}), \quad \text {. . . . . }
$$

in which $G$ and $P$ are constants. This furnishes by integration an equation of the form

$$
x=\text { const. }+\phi(\theta, \mathrm{G}, \mathrm{P}),
$$

which represents the law by which the temperature must change across the layer. What we learn from this investigation is, that, besides the uniform distribution of a gas with the 
same temperature everywhere, there is one other permanent distribution possible (except at the limits), and perhaps only one-that in it there is, for each gas and at each tension, a definite gradient of temperature, with its accompanying equally definite gradient of density in the opposite direction. These results might have been arrived at in another way, viz. by a consideration of the effects of the intermolecular encounters.

Another case in which the three conditions will be fulfilled is the familiar one of a uniform medium, in which case

$$
\frac{d \theta}{d x}=0 \text {, or } \theta=\text { const. . . . . }
$$

But if there is a transition from one of these distributions to the other, as there must be where the Crookes's layer is in contact with the rest of the gas, there will be an interval of compromise, in which the three conditions are not strictly fulfilled. Similarly, they cannot be fulfilled where the Crookes's layer adjoins the hot body $\mathrm{A}$. Hence there must, in the cases that really arise, be some escape of heat, which may be small, but cannot vanish, because discontinuity is impossible, since the length of the mean path of a molecule between its encounters with other molecules is finite. Hence, also, the values of the temperature at different depths within the Crookes's layer will differ by small amounts from those assigned to it by equation $(\beta)$. It will appear, however, from the next paragraph, that the rate of cooling arising from these imperfections will be very slow*; and although the heat that passes would doubtless accumulate and ultimately become considerable if there were no gravity, its presence will be inappreciable in most of the experiments we can make, where the portion of gas in which the Crookes's layer is formed is being constantly renewed by convection currents.

5. We have hitherto supposed that the atmosphere of gas was of sufficient extent to allow the whole of the Crookes's layer to come into existence; but we shall have entirely new conditions if a body $\mathrm{B}$ at temperature $\theta_{2}$, which for simplicity we may suppose to have a large flat surface, is placed parallel to $A$ at a distance less than the thickness of an unrestricted Crookes's layer. In this case a compressed $\dagger$ Crookes's layer will come into existence, in which, as explained in $\$ 16$ of my former papers, the density of the gas must be everywhere

* For, the Crookes's layer being in this case almost complete, the values of $\Delta \theta_{1}$ and $\Delta \theta_{2}$ (see $\S 5$ ) will be exceedingly small.

$\dagger I$. e. confined between a heater and a cooler, against which the layer of gas expends its Crookes's stress. In withstanding this stress the heater and cooler compress the layer. A compressed Crooles's layer might also be called a layer of polarized gas. 
greater than at the same distances from $\mathrm{A}$ in the complete Crookes's layer, to preserve the lateral pressure unchanged. Through each element $\delta S$ of an isothermal surface the molecules will still travel in equal numbers inwards and outwards, because when the adjustment is once over, the density of the gas will not anywhere undergo further change; but the molecules making their way outwards ( $i$. e. from A towards B) will, on the whole, be swifter than those tending inwards, because there should be a complete Crookes's layer to enable the swifter class of molecules rebounding from $A$ to keep back the whole of the slower kind which constantly tend to crowd in (see Phil. Mag. April 1876, p. 308, $\$ 15,16$, and 17). Accordingly, if the molecules at any one moment within an element of volume be considered, the portion of them which form a procession travelling inwards will now be found more numerous than those advancing outwards, and at the same time so much slower that the momentum in the two directions is the same; in other words, there is no molar motion of the gas, nothing in the nature of a wind. But that there is a continual transfer of kinetic energy from $A$ to $B$ across the intervening gas is evident, because members of the procession of colder molecules crowding up to A will cause the temperature $\theta_{1}-\Delta \theta_{1}$ of the inner surface of the Crookes's layer to be lower than $\theta_{1}$, the temperature of $\mathrm{A}$; while, at the same time, the members of the swift procession which reach $B$ will cause $\theta_{2}+\Delta \theta_{2}$, the temperature of the outside surface of the Crookes's layer, to be warmer than $\theta_{2}$, the temperature of $\mathrm{B}$. The Crookes's layer, accordingly, must acquire heat by its contact with $A$, and impart heat where in contact with $B$; and as adjustments within the layer are made with a speed comparable with the velocity of sound in the gas, it is possible to arrange experiments in which the differences of temperature $\Delta \theta_{1}$ and $\Delta \theta_{2}$ shall have any amounts from 0 -when the interval between $A$ and $B$ equals or exceeds the width of an unrestricted Crookes's layer, -up to values bordering upon $\frac{1}{2}\left(\theta_{1}-\theta_{2}\right)$-which, in the cases where the temperatures $\theta_{1}$ and $\theta_{2}$ are not far asunder, is close to the limiting value produced by diminishing the interval between $A$ and $B$, or by attenuating the gas.

Accordingly, if the variations of temperature were plotted down on a diagram, the ordinates representing temperatures, and the abscissas distances measured perpendicularly to the isothermal surfaces within the gas, we should obtain a figure something like that on next page. It is moreover manifest that the curve $n n$, representing the variations of temperature across the compressed or polarized Crookes's layer, will approximate more and more to a horizontal line the greater the tenuity of the gas. 
6. Some idea will be formed of the quantity of heat which will pass from $A$ to $B$ by the process here described, and for which I would suggest the name penetration, by forming an expression which aims at roughly representing the quantity of

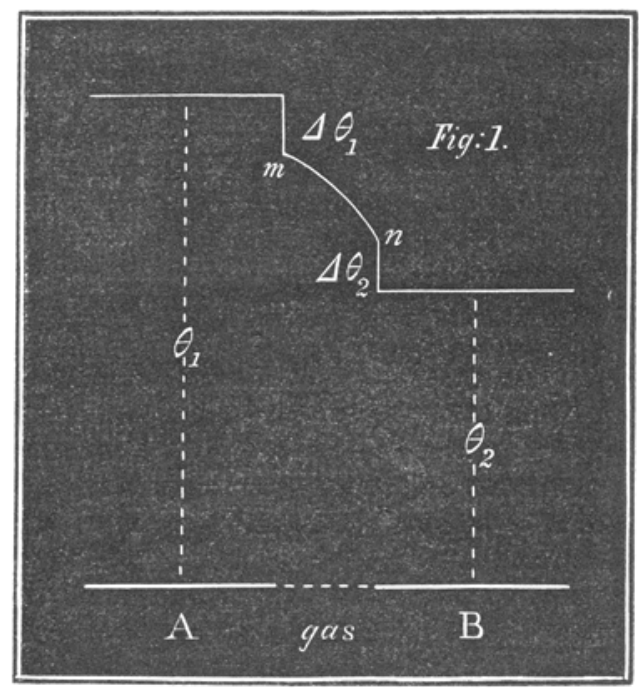

heat absorbed by the gas per second from a square centimetre of $A$. One such expression is approximately*

$$
\frac{d \mathrm{Q}}{d t}=\mathrm{V} \sigma \rho_{1} \frac{\Delta \theta_{1}}{\theta_{1}}, \ldots . \quad \cdot \quad \cdot \quad \cdot \quad \cdot
$$

in which $\mathrm{V}$ is the velocity with which the adjustment is made, $\sigma$ the heat which would raise a gramme of the gas one degree in temperature, and $\rho_{1}$ the density (referred to water) of the gas where it is in contact with $A$.

To get the loss by penetration per second from the whole surface of the cooling body, we have to find the value of the integral $\int \frac{d \mathrm{Q}}{d t} d \mathrm{~A}, d \mathrm{~A}$ being an element of the surface of the cooling body, and $\frac{d \mathrm{Q}}{d t}$ having the value assigned to it above. If the surface is everywhere equally exposed (a condition easily secured in making experiments with thermometer-bulbs), this

* To make the formula accurate, we should write $\int \frac{d \theta}{\theta}$ taken between the limits $\theta_{1}$ and $\theta_{1}-\Delta \theta_{1}$, instead of $\frac{\Delta \theta_{1}}{\theta_{1}}$, which is approximately its value when $\Delta \theta_{1}$ is small compared with $\theta_{1}$. 
becomes simply $\mathrm{A} \frac{d \mathrm{Q}}{d t}$, or

$$
\operatorname{AV} \sigma \rho_{1} \frac{\Delta \theta_{1}}{\theta_{1}}, \text {. . . . . . }
$$

where $A$ is the area of the surface of the cooling body.

7. It will be instructive to compare the loss of heat by penetration with the quantity which is carried off by convection. To estimate the latter, let $\Omega$ be the section of the convection current, $\rho$ its average density, $\Delta \theta$ the average excess of its temperature, and $v$ its velocity. Then the total quantity of heat which will be removed per second by convection will be

$$
\Omega v \sigma \rho \frac{\Delta \theta}{\theta} \text {. . . . . . . }
$$

This is to be compared with ( $\epsilon)$, the expression for the total loss of heat per second by penetration.

Now, in the cases that occur in laboratory experiments, $A \sigma \rho_{1}$ is seldom many times larger or many times smaller than $\Omega \sigma \rho$, but $\mathrm{V}$ is always very much larger than $v$, whence $(\epsilon)$ may have a value comparable with ( $\zeta)$ while $\Delta \theta_{1}$ is very much less than $\Delta \theta$-in other words, when the processions between the opposed surfaces have but slightly different velocities. We learn from this that the escape by penetration may be expected to manifest itself as soon as the Crookes's layer has become in a moderate degree compressed *. It is also evident that the coexistence of a convection current will not much affect the escape of heat by penetration, inasmuch as convection currents are sluggish when compared with the promptness with which readjustments are made in Crookes's layers. It is therefore worth while to examine the numerous records of experiments upon the velocity with which bodies cool in gases, with a view to finding whether instances of the escape of heat by penetration can be found among them.

\section{PART II. Interpretation of Experiments.}

8. Accordingly I made a search of this kind last year, shortly after the publication of my two papers in the 'Philosophical Magazine,' but without finding any records more to the purpose than those by Dulong and Petit of experiments with hydrogen, which will be cited below; and as these, taken by themselves, did not seem sufficiently decisive, I postponed publishing further on the subject until I should have leisure to make experiments myself. But before this leisure came, Mr. George F. Fitzgerald met with a brief notice in Jamin's Physique, of experiments by De la Provostaye and Desains, which appeared to him to contain observations on the pene-

- Hence also thermal experiments may be expected to explore Crookes's layers with more sensitiveness than contrivances for manifesting the mechanical force which is also present. 
tration of heat; and on referring to the original memoirs, first published more than thirty years ago in the Comptes Rendus, and afterwards with somewhat more detail in the Annales de Chimie* , I had the pleasure of finding the record of two elaborate experimental investigations into what we now know to have been the penetration of heat. At that time the experimental results were regarded as anomalous ; and the only conjecture which De la Provostaye and Desains put forward is that they may in some way depend on the swiftuess of convection currents in attenuated gases $\uparrow$. It is, however, easy to see that no such increased swiftness as can exist will account for the observed phenomena. Mr. Fitzgerald was unable to spare the time necessary to follow up the subject, or he would have joined me in working out this part of the present memoir; but to him is due the whole credit of having perceived the importance of these observations, and to his kindness I owe the advantage of having had my attention directed to them and the permission to make use of them, as I now do.

9. Dulong and Petit, experimenting with large thermometer-bulbs placed at the centre of a hollow copper globe 30 centims. in diameter, blackened on the inside and kept at a constant temperature, observed the rate at which the thermometer, after having been warmed, cooled in different gases, at different tensions, and with the bulb naked or coated in various ways. From these experiments they obtained their well-known empirical law for the escape of heat by radiation and convection. The expression which they give consists of two terms; of which one represents the velocity with which heat escapes by radiation, and the other the velocity with which it escapes by convection, or, as we shall presently see, in some cases by convection and penetration. We have here no concern with the first of these two terms, further than to observe that the escape by radiation is the same at all tensions of the gas and for all dimensions of the receiver, and depends only on the character of the surfaces exposed, on $\theta_{2}$ the temperature of the copper globe, and on $\theta_{1}-\theta_{2}$ the excess of temperature of the thermometer. For given values of $\theta_{1}$ and $\theta_{2}$ it was accordingly a constant at all the tensions and with all the receivers

* Comptes Rendus, vol. xx. (1845) p. 1767, and vol. xxii. (1846) p. 77 ; Annales de Chimie, third series, vol. xvi. p. 381, and vol. xxii. p. 362 .

$\dagger$ De la Provostaye and Desains conclude their second memoir in the following words:-"Nous ne chercherons à donner une explication complète des différents faits cités dans cette communication. Nous ferons remarquer seulement que le pouvoir refroidissant d'un gaz dépend de sa densité et de sa mobilité. Ces deux éléments varient en sens inverse quand on change la pression, et l'on conçoit que les effets de ces variations contraires puissent tantôt s'équilibrer, tantôt se surpasser dans un sens ou dans l'autre." 
which De la Provostaye and Desains used, and in the following diagrams is represented by the interval between two horizontal lines. This interval is, moreover, small, because De la Provostaye and Desains reduced the loss by radiation to a very small amount by silvering or gilding the bulb of their thermometer.

The other term of Dulong and Petit's expression, which furnishes the rate of escape by convection, is

$$
\mathrm{K} p^{c} \text {; }
$$

where $p$ is the tension measured in millimetres of mercury, $\mathrm{K}$ depends on the gas and on $\theta_{1}$ and $\theta_{2}$, and $c$ was found to be nearly $\frac{1}{3}$ when the receiver contained hydrogen, but was nearly $\frac{1}{2}$ for the other gases experimented on and for atmospheric air. I will return to the case of hydrogen; but in the other gases the velocity of the escape of heat by conrection with given temperatures of the bulb and receiver will be represented at different tensions of the gas by the ordinates of a curve not differing much from a parabola, since this would be the curve if the index were exactly $\frac{1}{2}$; and, accordingly, curves of this kind are laid down in the annexed diagrams. It is not material whether a large or a small portion of the parabola is introduced, because all parabolas are similar.

10. By thus plotting down the results of the experiments upon diagrams, we obtain the means of seeing at a glance how much of the escape of heat observed by De la Provostaye and Desains can be accounted for by radiation and convection, and how much remains to be allotted to penetration. De la Provostaye and Desains made their observations in three receivers-a hollow sphere of 24 centims. diameter, a hollow sphere of 15 centims. diameter, and a cylinder 6 centims. in diameter and 20 centims. in height; and they used in all the receivers the same thermometer, which had a cylindrical bulb 7 centims. long and 2 centims. across*. Accordingly the interval between the bulb and the walls of the receiver ranged from $8 \frac{1}{2}$ centims. up to 11 centims. in the largest receiver, from 4 centims. up to $6 \frac{1}{2}$ centims. in that of intermediate size, and was 2 centims. in the cylinder.

In Dulong and Petit's experiments the diameter of the receiver was 30 centims., and they used thermometers with spherical bulbs 2 and 6 centims. in diameter, so that the interval was either 12 or 14 centims.

11. With atmospheric air in the largest receiver (in which

* The direction in which the heat penetrates, and of the Crookes's stress, will be perpendicular to the isothermal surfaces within the gas in the simple case which we have hitherto considered, where $A$ is parallel to B; but it will in general pierce the isothermal surfaces obliquely if one part of the Crookes's layer is more curtailed than another. 
a Crookes's layer of a width of $8 \frac{1}{2}$ centims. would reach the walls at two points, and any wider Crookes's layer would be curtailed), De la Provostaye and Desains found that the rate of cooling, or the escape of heat per second, which is proportional to it, was represented by Dulong and Petit's expression (which had been based on experiments made with intervals of 12 and 14 centims.) until the exhaustion reached 6 millims. of mercury, but that, after passing that tension, the rate of cooling, instead of continuing to decrease, remained sensibly constant between tensions of 6 millims. of mercury and $2 \cdot 8$ millims. (the lowest tension at which they experimented). This is represented on fig. 2 by the horizontal line from $m$ to $n$. In this figure the abscissas represent tensions in millims. of mercury, and the ordinates of the thick line represent the observed rates of cooling at different tensions but with constant valnes of $\theta_{1}$ and $\theta_{2}$. The part of the ordinate between the horizontal lines represents the escape by radia-

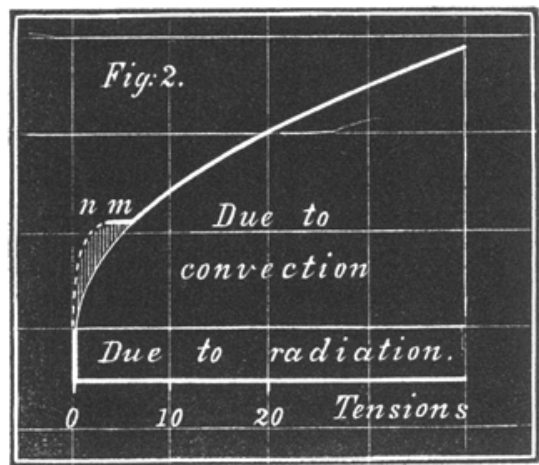

The sladed part is to be attributed to penetration. tion; its continuation up to the parabola represents the escape by convection; and the extension upwards into the shaded portion of the figure is due to the penetration of heat across the Crookes's layer, which evidently reached the walls of the receiver when the tension was reduced to about 6 millims., and was compressed when the exhaustion proceeded further.

Similarly with the receiver of intermediate size, in which a Crookes's layer of a width of 4 centims. would reach the walls, the results obtained by De la Provostaye and Desains are represented graphically by fig. 3 . In this case heat leaked away by penetration in appreciable quantities at tensions under 20 millims. of mercury, and kept the total

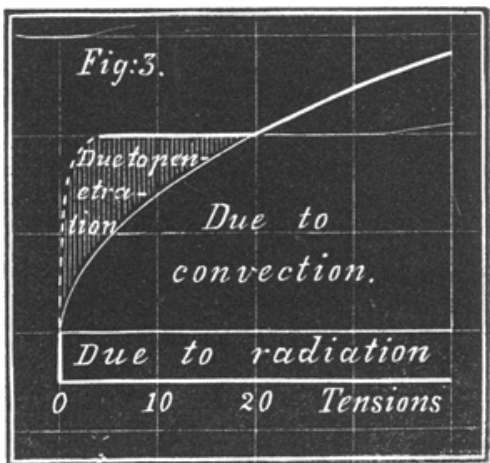

Phil. Mag. S. 5. Vol. 4. No. 27. Dec. $1877 . \quad 2$ F 
escape of heat nearly constant between tensions of 20 and 4 millims.

12. But the most decisive experiments were made with the cylindrical vessel, which was the smallest of the three receivers. In it the interval between the bulb and the walls of the vessel was only 2 centims.

With this vessel the rate of cooling was slower than in the two larger receivers at all tensions from 760 millims., or the tension of an atmosphere, down to about 45 millims. This seems to indicate that the convection currents were impeded by the form and small size of the cylinder; so that if the ordinates of the parabola $0 r$ represent the rate of cooling which would result from convection in a large vessel, the ordinates of some lower curve such as $\mathrm{O} m$ will represent the rate due to convection in the cylinder. The observations recorded by De la Provostaye and Desains enable us to fix the points $m, r$, and $n$, corresponding to the tensions 70,45 , and 15 millims., nearly in a horizontal line. They also state that near the tension of 6 millims. the rate of cooling diminished with "excessive rapidity," but that nevertheless at a tension of 2.8 millims. it still exceeded by a large amount that which presented itself at the same tension in their largest receiver, and which is represented in fig. 2. These statements indicate that the observations, if plotted down, would have given a curve like the thick line of fig. 4. It is hardly necessary to point out that

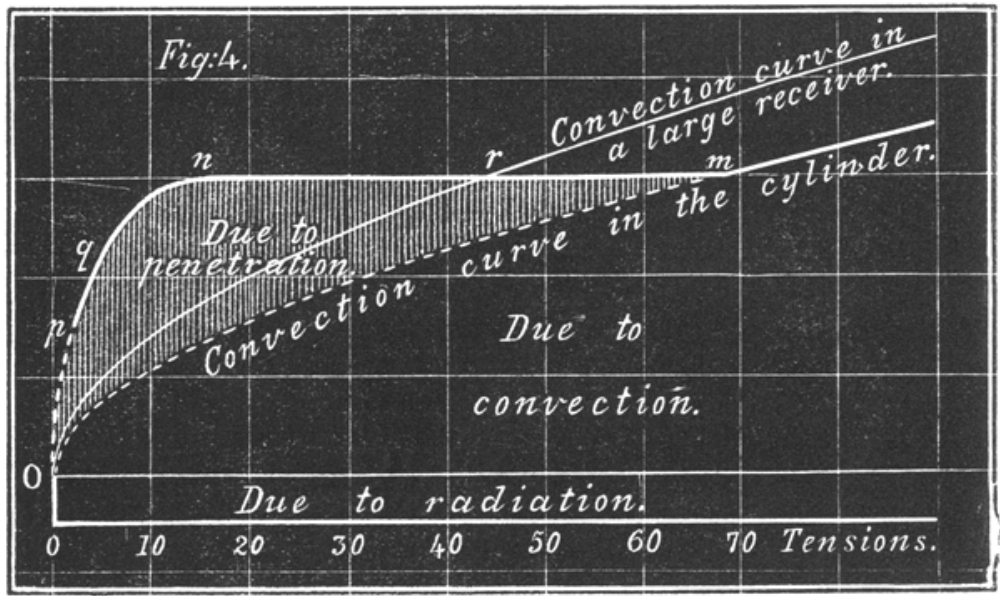

the larger development of the phenomenon, and its exhibiting itself at higher tensions with each diminution of the size of the receiver, as shown in the foregoing diagrams, are in the 
most satisfactory accordance with the theory presented in this memoir.

13. If we suppose the shaded portions of the ordinates in fig. 3 to be moved vertically downwards till they abut upon a horizontal axis of abscissas, we shall obtain the curve in fig. 5 ,

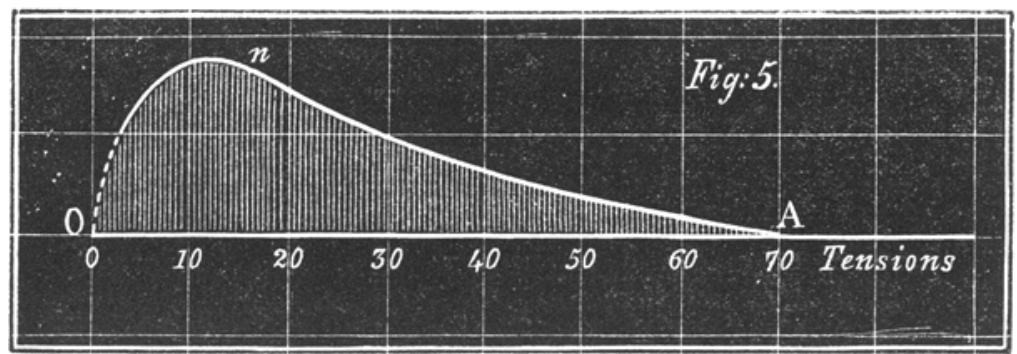

the ordinates of which represent the rate at which heat escaped by penetration in De la Provostaye and Desains's cylinder, separated from the effects of radiation and convection.

We can only compare this figure in a very general way with the formula given above for the escape of heat by penetration, viz.

$$
\frac{d \mathrm{Q}}{d t}=\mathrm{V} \sigma \rho_{1} \frac{\Delta \theta_{1}}{\theta_{1}}, \ldots
$$

because too little is known of $\mathrm{V}, \rho_{1}$, and $\Delta \theta_{1}$ to enable us to plot down a curve from this expression*. But we can, at all events, see that $V$ will be only moderately affected by alterations of tension, that $\rho_{1}$ will vary nearly as the tension, and that as the tension is diminished $\Delta \theta_{1}$ will gradually rise from 0 to a value which is nearly $\frac{1}{2}\left(\theta_{1}-\theta_{2}\right)$. Hence the curve must be one somewhat like that of fig. $6 \uparrow$, whose ordinates first rise gradu-

* Just as the parabolic curve of convection could not have been plotted down from equation $(\zeta), \S 7$, owing to the vagueness of some of the quantities which appear in it, viz. $\Omega, v$, and $\Delta \theta$.

$\dagger$ In fig. $6,0 \mathrm{~B}$ is intended to represent a portion of the curve $y=V \sigma \rho_{1} \frac{1}{2} \frac{\theta_{1}-\theta_{2}}{\theta}$, and $O n A$ the result of shortening its ordinates in the ratio $\frac{\Delta \theta_{1}}{\frac{1}{2}\left(\theta_{1}-\theta_{2}\right)}$.

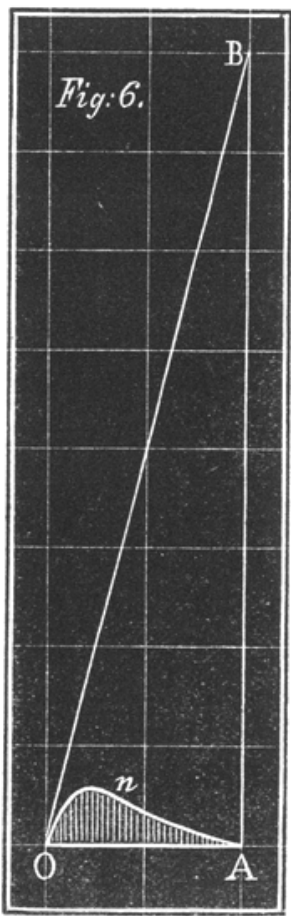


ally to a maximum at a certain tension, after which they fall away to cipher if the exhaustion is continued indefinitely. This description agrees with the form determined from the observations and which is plotted down in fig. 5 ; so that the comparison, though necessarily very imperfect, lends support, so far as it goes, to the conclusion that the apparently anomalous escape of heat which De la Provostaye and Desains investigated was due to penetration.

14. Hitherto I have used only the observations recorded in the memoir first published in the Comptes Rendus for 1845 . In their second memoir, first published in the Comptes Rendus for 1846, De la Provostaye and Desains record observations made with the silvered thermometer within their blackened cylinder, charged successively with hydrogen, carbonic anhydride, protoxide of nitrogen, and a mixture of air and hydrogen.

In carbonic anhydride the results of experiments are represented by fig. $7^{*}$. In this gas the total rate of cooling in-

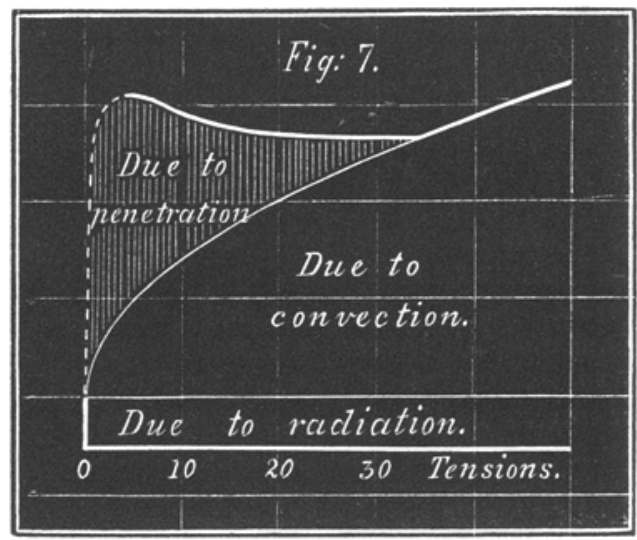

creased when the tension was diminished from 12 to 4 millims. This observation took De la Provostaye and Desains so much

* De la Provostaye and Desains record the following observations, from which the curve in the text has been plotted down, the ordinates being drawn proportional to the reciprocals of the observed times of cooling:-

\begin{tabular}{|c|c|c|c|}
\hline Tensions. & 35 millims & 12 millims. & 4 millims. \\
\hline Times. . & $\begin{array}{cr}\mathrm{m} & \mathrm{s} \\
19 & 42\end{array}$ & $\begin{array}{rr}\mathrm{m} & \mathrm{s} \\
19 & 38\end{array}$ & $\begin{array}{rr}\mathrm{m}_{17} & \mathbf{s} \\
59\end{array}$ \\
\hline
\end{tabular}

The reciprocals are proportional to 282,283 , and 309 . 
by surprise that they repeated and varied their experiments, till they were fully satisfied that the existence of the increased escape of heat was proved.

With protoxide of nitrogen $\left(\mathrm{N}_{2} \mathrm{O}\right)$, a gas which has the same specific gravity as carbonic anhydride, their observations gave similar results. Between tensions of $\ddot{3} 5$ inillims. and 12 millims. the total rate of cooling remained nearly constant; and, as in carbonic anhydride, it was slightly increased by further diminishing the tension from 12 down to 4 millims. This slight increase was less in the protoxide of nitrogen than in the carbonic anhydride-about $\frac{1}{24}$ of the whole amount in the former gas, about $\frac{1}{12}$ in the latter.

The observations with these gases show that the form of the curve represented in fig. 5 is in an appreciable degree different in different gases, and that there are some gases in which the increase of the escape of heat by penetration when the tension is decreased will, within certain limits of temperature, exceed the decrease of the escape of heat by convection.

15. We now come to the very remarkable results which were obtained with hydrogen. They are plotted down in fig. 8 . A Table of some of the results of the observations, and the following particulars recorded by De la Provostaye and Desains enable us to construct this figure. The loss of heat by radiation from the silvered bulb was only $\frac{1}{18}$ of the wholo amount (presumably at 760 millims. tension). The rate of cooling at 20 millims. tension was found to be $\frac{11}{12}$ of that at 760 millims. The rate of cooling at a tension of 12 millims. was rather more than 11 of that at 20 millims. At 4 millims. it fell to about one half; and nevertheless, when the rate of cooling at this lowest tension was compared with that of a similar bulb placed in the open air, it was found to exceed the latter in the proportion of 4 to 3 . We thus get from the observations* all parts of the figure except those entered in dotted lines. The curve representing the loss by convection must lie

* The following observations are recorded by De la Provostaye and Desains:-

\begin{tabular}{|c|c|c|c|c|c|}
\hline Tensions & $\begin{array}{c}760 \\
\text { millims. }\end{array}$ & $\begin{array}{c}477 \\
\text { millims. }\end{array}$ & $\stackrel{57}{\text { millims. }}$ & $\stackrel{20}{\text { millims. }}$ & $\begin{array}{c}4 \cdot 4 \\
\text { millims. }\end{array}$ \\
\hline Times of cooling.. & $\underset{12}{\mathrm{~m}} \stackrel{\mathrm{s}}{46}$ & $\begin{array}{c}m \\
13\end{array}$ & $\mathrm{~m}_{13} \stackrel{\mathrm{s}}{40}$ & $\underset{14}{\mathbf{m}} \underset{49}{\mathrm{~s}}$ & $\mathrm{~m}_{27}^{\mathrm{s}} 24$ \\
\hline
\end{tabular}

The rates of cooling will be as the reciprocals of these times, $i . e$. as the numbers $652,625,610,562$, and 304 respectively ; and to these numbers the corresponding ordinates of the upper line in our figure have been made proportional. 
in the upper line of fig. 9, to represent the observed excess of the escape of heat over what was accounted for by radiation

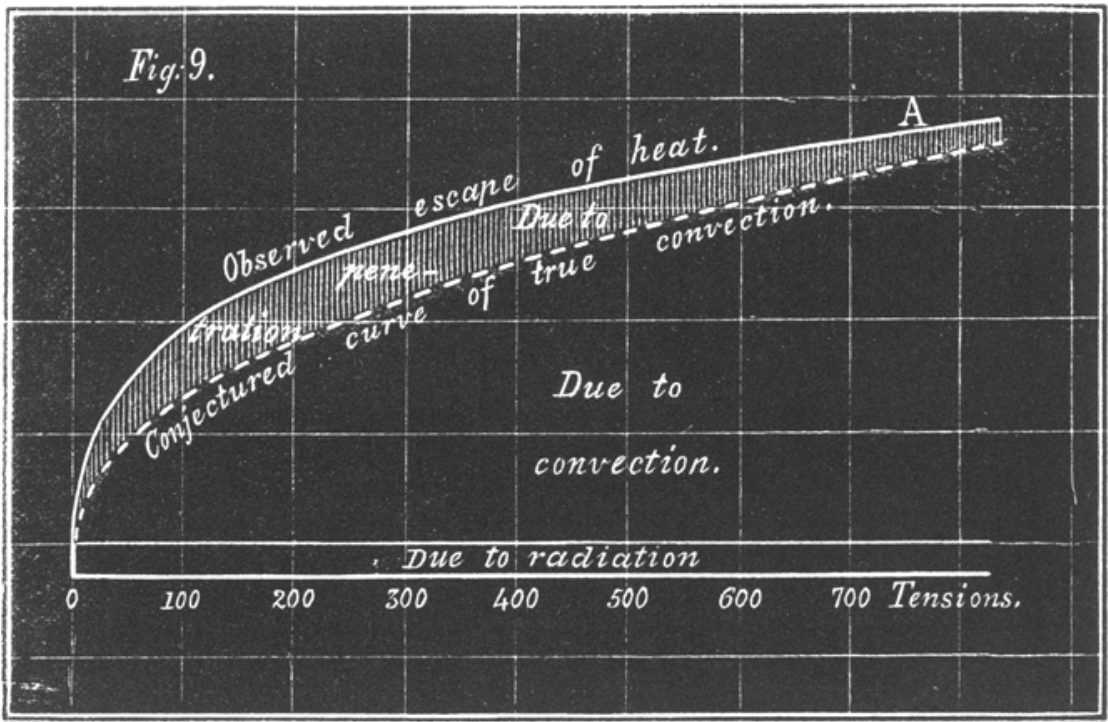

we may draw the dotted parabola crossing it somewhere to the right of $A$, and conclude that the convection, if it could be separated from penetration, would be represented by the ordinates of such a curve, and that the shaded interval betwoen the two curves is due to heat having leaked away by penetration, across even so much as 12 centims. of hydrogen. Although we cannot assign the exact position of the dotted line until observations shall have been made in larger receivers, we can already see the general shape of the shaded space which is at present the object of our search.

17. In a mixture of air and hydrogen within the cylinder, De la Provostaye and Desains found that at a tension of 60 millims. the rate of cooling was "much less" than if the hydrogen alone had been present. From this, and from the observations plotted down in fig. 8 , it follows that the Crookes's layer in such a mixture is narrower than if all the molecules present had been hydrogen. This accords with the theoretical consideration that the members of both the processions in the hydrogen will be more diverted from their course, and will therefore transmit forward less of their own momentum and vis viva, if some of the molecules they encounter are the heavier molecules of other gases.

18. Several phenomena observed by Grove, Tyndall, Mag- 
nus, and others, have been attributed to copious conduction of heat through hydrogen. May we not with more probability refer them to the very remarkable power which hydrogen possesses of allowing heat to leak away by penetration? From the dynamical theory of gases, it seems improbable that any gas can possess true conducting-power in a high degree; and every observer must have been struek by the violence of the first chilling effect in some of these experiments, and the unflagging energy with which it is maintained, a promptness and persistence characteristic of penetration, but quite unlike the moderate initial effect and diminished subsequent progress which we should expect from condaction.

19. One of the most striking of these experiments is that by Sir William Grove, which exhibits the cooling effect of hydrogen on a wire rendered incandescent by the passage of an electric current; and according to the hypothesis here presented it ought to be possible to repeat this experiment in ordinary atmospheric air by bringing the incandescent wire sufficiently close to a cool object. This very instructive experiment was proposed by my son, Master Gerald Stoney, and has been successfully performed by him. He first passed the wire through a glass tube drawn out sufficiently thin. The effect could then be seen; but it was evanescent, because the glass became rapidly heated. No doubt, if the tube had been surrounded by a water jacket, the experiment might have been made in this way satisfactorily. But he made it in an equally permanent form, and with greater ease, by simply bringing the incandescent wire close to a tin can containing water, to which the heat leaked away abundantly from the wire when the intervening stratum of air was sufficiently thin. The effect is best seen when the wire is of a dull red, on account of the ease with which the eye detects the difference between dull red and darkness. It then becomes conspicuous when the interval is a millimetre, and can be perceived when the interval is considerably more. In this experiment the can was at a slightly higher temperature than the room. On this account, and because a small part of the radiated heat was reflected back on the wire by the tin, the loss of heat by radiation was less than when the can was away; moreover the convection current was enfeebled by being both cooled and obstructed by the neighbouring obstacle. Hence the true loss of heat by penetration must have been in excess of that which manifested itself.

20. Another phenomenon which admits of explanation by the theory developed here and in my former papers, is one which is said to have caused the bursting of steam-boilers, 
which is familiar to us as the way in which a laundress tests the heat of her smoothing-iron, and which was studied by $M$. Boutigny under the name of the spheroidal state of liquids. If a drop of water or other cold volatile liquid is allowed to fall into a smooth and sufficiently hot metal dish, it continues liquid instead of flashing off into vapour, and exhibits an appearance of great mobility. Here the liquid settles down upon the Crookes's layer which envelops the metal, and reduces that portion which is under it to the condition of a compressed Crookes's layer. Now the mechanical peculiarity of a compressed Crookes's layer is, that it exerts more force in the direction along which the heat travels (in the present instance up and down) than in the perpendicular direction; and inasmuch as the pressure sideways must continue to be the pressure of the atmosphere, the excess of pressure upwards is able to support a weight. When we also remember that this excess of pressure would be augmented by still further curtailing the Crookes's layer, $i$. e. by depressing any part of the drop, we have all the mechanical conditions necessary for the stable equilibrium of the drop, if only the force rises to a sufficient amount before the drop settles down quite through the Crookes's layer. This, by the theory, depends altogether on the difference of temperatures which can be maintained. The first thermal effect is, that the drop becomes warmed by the radiation and penetration of heat from the hot metal below. This canses the liquid, if volatile, to lose heat by evaporation, and, in most cases, to lose a little heat also by radiation to surrounding bodies. As the temperature of the drop rises, the heat thus lost increases, while at the same time the heat received from below diminishes, and if a balance between the two is effected before the liquid reaches the boiling-point, the drop continues liquid, the temperature remains henceforth unchanged, and we have before us the striking spectacle of a liquid in the spheroidal state.

21. I have long thought it likely that the drops which may be sometimes seen running over the surface of a volatile liquid are supported by compressed Crookes's layers intervening between them and the liquid on which they float-that they are, in fact, drops in the spheroidal state; and the following observations abundantly confirm this suspicion. These floating globules are easily formed when a liquid as volatile as spirits of wine is allowed to fall in drops of a medium size from a height of about 8 centimetres into a vessel containing some of the same liquid moderately warmed*. They can also be

* A better way to form them is gently to lay the drop as it were with a fine pipette upon the surface of the heated liquid. The drop when 
occasionally produced by dropping the spirits of wine upon water. And every one is familiar with them when, in some states of the weather, they roll about in numbers on allowing water to drip from an oar upon the sea. Recently they were abundantly produced by splashing the water of a neighbouring pond; and $\mathrm{I}$ took advantage of the opportunity to ascertain that the conditions required by the hypothesis were fulfilled. The temperature of the air was about $15^{\circ}$, that of the surface of the water $18 \frac{1}{4}^{\circ}$; and a very dry breeze was blowing, which so facilitated evaporation from the drops* that they probably maintained a temperature as low as $10^{\circ}$, a temperature which my thermometer reached when I left a damp weed in contact with one side of the bulb.

When globules of methylated spirit were formed upon a beaker nearly full of the same liquid, which was progressively warmed, it was found that, when the air was still, there was a particular temperature at which the drops were most persistent. At this temperature some lasted for as long as twelve or fourteen seconds. As the temperature rose beyond this point, the atmosphere of vapour impeded evaporation and the persistence of the drops became less ; but by gently blowing on the surface so as to accelerate the evaporation, it was found possible to keep some of the smaller drops in existence for two or three minutes $\dagger$, during which time they very slowly dwindled away till they were very minute, and then suddenly vanished. When the temperature of the beaker full of spirit was allowed to fall below the point above referred to, the duration of the drops also became progressively less ; but they could still be formed, though short-lived, at a temperature a little below that of the room.

From this, and from the circumstance that I succeeded in forming some within a bottle of methylated spirit which had been standing open for a while, and within which evaporation must have been feeble, it is evident that a drop can be sup-

formed can be fed from the pipette and so greatly augmented in size. When in this way the drop is made so large as to be very much flattened out, tremulous motions arise similar to those which Boutigny observed in his spheroidal drop, but less violent.

* The liquid on which the drops rest is no doubt also cooled by evaporation, but in a trifling degree, because convection currents constantly bring to the surface an accession of warm liquid from below.

$\dagger$ In four better-arranged experiments, since made in the laboratory of the Royal Dublin Society by Mr. R. J. Moss and myself, and of which we hope to give an account to the Society, we succeeded in maintaining similar drops of larger size formed on methylated ether for ten, fourteen, sixteen, and twenty-six minutes, respectively ; and we believe that it will not be difficult, by securing a greater constancy in the conditions indicated by the theory, to prolong their existence very much more. 
ported with but a slight difference of temperature between it and the liquid on which it rests. In this respect the spheroidal state on liquids differs from that in which the drop rests upon a heated solid. The difference of behaviour is probably due to the deformation of its natural spherical shape to which a drop is compelled to submit when it rests on a rigid surface. Owing to this constraint the surface-tension over the drop will force some parts into closer contact; and, moreover, the vibrations which always arise in this case must tend to a similar result. On the other hand, when the drop is resting on a liquid, it settles tranquilly into a beautiful concave socket that can be seen by looking at the surface of the fluid from beneath. This socket allows the globule to retain a nearly spherical and therefore unconstrained form; and, accordtngly, the opposed surfaces come within an approximately equal distance of one another throughout a large arc. And it is evident that as the whole pressure arising from the molecular motions in the air would support a column of spirits of wine $11 \frac{1}{2}$ metres high, it needs only a very moderate Crookes's polarization of the stratum of air to furnish that slight preponderance of momentum in a determinate direction which is required to support the few additional millimetres that correspond to the weight of the drop. We must remember, too, that a drop may, under favourable circumstances, outlive the difference of temperature, because it would take a sensible time for so slight a pressure as the weight of the drop to squeeze the film of air, when once established, out of its narrow chink. Even a heavy metal proof-plane will float over another proof-plane, upon the stratum of air entangled between them, for a considerable time.

22. Professor Barrett has called my attention to another unexplained phenomenon, of which we can now see the cause, viz. the mobility imparted to a very fine powder (as, for example, magnesium carbonate or precipitated silica) by heating it in a metal dish. When the dish is disturbed the powder glides about as if floating; and it is in fact floating on the compressed Crookes's layer, which will spring into existence whenever the powder is able by radiation to maintain a lower temperature than the dish.

23. The communication of heat by penetration is a very familiar phenomenon ; for when surfaces at different temperatures are brought into what is commonly called contact, there is usually a thin intervening stratum of air, except at special points ; and, accordingly, the greater part of the transfer of heat, so long as the difference of temperature is considerable, must be effected, not by contact, but by penetration across a Crookes's layer. 